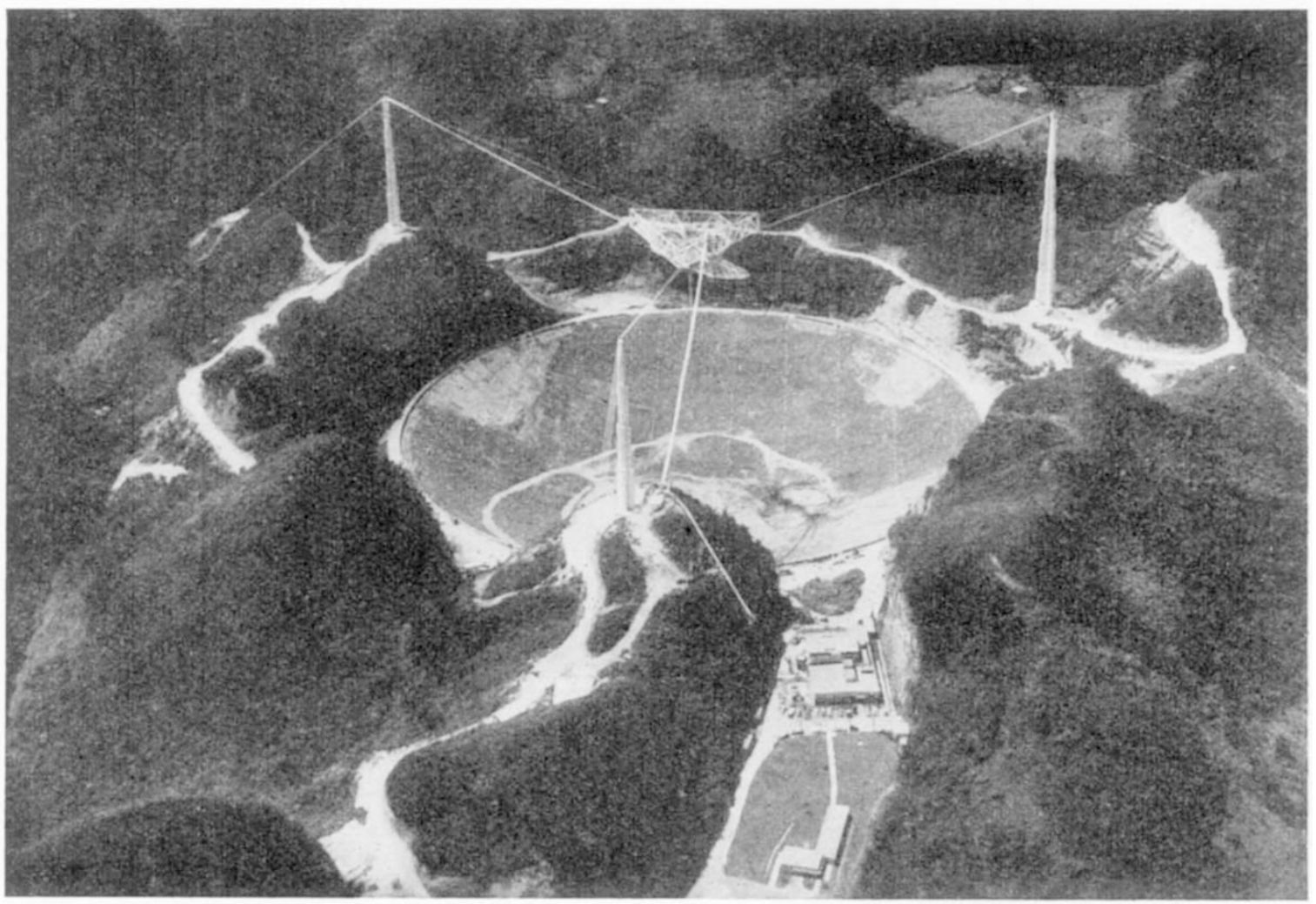

Fig. 2. Aerial picture of the giant radar radio telescope at Arecibo in Puerto Rico. The spherical dish antenna is 1,000 ft.in diameter and the movable feed arm is suspended on cables some $500 \mathrm{ft}$. above it from three concrete towers, two of which are 265 ft. in height the movable feed arm is suspended on cables some $500 \mathrm{ft}$. above it from three
and the third $365 \mathrm{ft}$.

It has been shown that such invostigations have the possibility of giving information concerning the structure of the universe on the largest scale and, therefore, about cosmology.

Investigations of this kind have been made several times in the past, and have been severely disturbed by a variety of errors. It is now considered that such catalogues of sources ought to be published, so far as possible, only after each source has been investigated separately by two different instruments which are unlikely to suffer from similar deficiencies and which work on approximately the same frequency. A large area-filled instrument like a dish and an open area instrument like a Mills Cross make an ideal pair in this respect. It is proposed, therefore, to prepare a detailed catalogue of sources in the area of sky in which the Sydney Mills Cross and the Arecibo instrument overlap. All discrepancies between the results of the two instruments will be investigated in detail, and the final catalogue should be of a level of precision far exceeding that of any previous work.

Other investigations where a joint operation is clearly advantageous are those of extended sources and back- ground structure where more detail can be described by using two such instruments than by either singly.

These examples of joint observation are those which come to mind in the present state of the instrumentation. It is expected, however, that many other types of observations will equally benefit as the subject advances and as the instrumental facilities available increase. Furthermore, one may look forward to new research projects coming forward as the full effect of the joint team effort comes to fruition.

The two universities have agreed to recognize researeh supervision extended by the sister institute and with the approval of the home research supervisor, and the time spent by a student on thesis work in the sister institute. will be accepted toward the residence requirement.

The scientists concerned are agreed that such a joint operation would be most beneficial for their work and for the subject, for the reasons mentioned. An oporation of this kind, where the advantages to research are con. spicuous, may pave the way towards other combined university operations which tend to break down barriers imposed by geography and thus broaden the educational programme.

\title{
OBITUARIES
}

\section{Dr. R. S. Creed}

His many pupils will havo road with regret of the death on July 7 at his home near Oxford of Dr. K. S. Creed, emeritus Fellow of New College, Oxford, and formerly demonstrator and lecturer in the Department of Physiology, University of Oxford. $\mathrm{H}_{\theta}$ was in his sixty-fifth year and is survived by his wife, herself a distinguished physiologist, a son who was elected to a Grocer's Company research fellowship in zoology at New College this year, and three daughters.
Dr. Creed went up to Trinity College, Oxford, in 1916 and, after service with the Royal Field Artillery in France and Belgium during tho next two years, returned to take a first-class degree in the Honours School of Natural Science (Physiology) in 1921, winning a serior demyship at Magdalen and the Gotch Memorial Prize. $\mathrm{H}_{\Theta}$ took his clinical training at St. Thomas's Hospital and gained the B M., B.Ch. and Conjoint qualifications in 1923. He was elected to a fellowship at Now College at the age of 27 , and served the College for many years as stoward, pre- 
centor, editor of the college record, sub-warden, and as a Fellow of Winchester College. Ho took the D.M. in 1930 and was awarded the Radcliffe Prize in 1933. Between the two World Wars Dr. Creed was an active Territorial officer; he was called up for service with the Royal Army Medical Corps in 1939 and served overseas in the Middle East and Italy. He returned to Oxford in 1945 and from 1947 until 1960 was chairman of the management committee of the Warneford Hospital. In 1949 he joined tho editorial board of the Journal of Physiology, at a time of rapid post-war expansion, and was chairman from 1951 until 1956, a position of particular responsibility in maintaining that Journal's high standards. He was president of the physiology section of the meeting of the British Association for the Advancement of Science in 1955.

Dr. Creed was a co-author of the Reflex Activity of the Spinal Cord, a physiological classic published in 1932 with Denny-Brown, Eccles, Liddell and Sherrington. He made a number of contributions to the analysis of inhibitory reflexes, and also to investigations of the latency of after-images and of the electro-retinogram with Ragnar Granit. He was particularly interested in the mechanism of hearing and the function of the vestibular apparatus. However, above all, he was a College tutor in the classic tradition who would listen to an essay without interruption, and then, by a few deft and disconcerting questions, demonstrate the value of succinct expression and critical evaluation. Many generations of New College medical undergraduates have owed him a lasting debt for his perceptive and friendly guidance.

G. S. Dawes

\section{Mr. Lauge Koch}

Tre Danish geologist Lauge Koch, who died on June 7 aged seventy-two, was a legendary figure among Arctic geologists (themselves noted for strong characters). His first geological expedition was in 1913; then he was back in Greenland in 1916 with the veteran explorer Knud Rasmussen with the Thule Expedition which was marooned in north-west Greenland until after the First World War ended. Despite the hardships of this expedition (on one journey they ato thoir starving dogs and a member died) he returned to the same district to lead his own expedition. I met him a good many years later when $I$ joined his party in Scorosby Sound in 1926-27. He had undertaken all the work of planning, stocking the party for the year and choosing tho men-the Danish geologist Rosenkrantz, two Eskimo hunters and myself as a specialist on fossil plants. It was Koch who made the long sledge journey in late winter; he left to us shorter journeys and detailed work.

Koch was a big strong fellow, happier on a dog sledge than anywhere else. His character had much strength and half-a-dozen bad sides of which he was cheerfully aware and which all could see; but for me it was saved by his robust and often generous sense of humour. Very likely, too, the partial language barrier made relations easier. I am sure men will long brighten the Greenland night by anecdotes of Lauge Koch, stories that may or may not be true, just as Koch's own stories were. So he would have wished it to be.

Koch continued to lead expeditions for many years. As he grew old he managed to avoid the most exacting physical exertions, but he remained very much the leader. $\mathrm{He}$ wanted to complete the picture of the geology of Greenland, and, while he tolerated detail by other hands, his part was to be painted with bold strokes. I doubt if he evor spent months working on one rock formation to porfect knowledge that was already fairly good.

It was natural that he should undertake the work of writing a comprehensive account of the geology of Greenland. Nevertheless, he was the wrong man to do this. Though he had done more than anyone else, his boldness with theory bordered on rashness; it is said he had not the patience to confirm facts, and, worse, that he failed to attribute to others what was due to them. I do not know the truth, but he had already antagonized many (a thing that troubled him not at all) and there was a published counter-blast, a libel action and a hideous row which split Danish geology for years.

No more pioneering work like Koch's remains to be done, and now an aeroplane can do in an hour what a dog sledge took a month to do. But when the next comprehensive work on the geology of Greenland is written I am sure that by far the longest list of entries. will be under Koch's name.

TOM M. HARRIS

\section{NEWS and VIEWS}

Research and Development, U.S. Coast and Geodetic Survey: Dr. John S. Rinehart

Dr. John S. RINeHART, former director of the Mining Research Laboratory, Colorado School of Mines, has been appointed to direct the Office of Research and Development of the U.S. Department of Commerce Coast and Geodetic Survey. He succeods Dr. Christopher E. Barthel, jun., who left the Survey to become executive director of the Kansas Research Foundation at Topeka. As assistant director for research and development, Dr. Rinehart will be concerned with the expansion of the Survey's scientific responsibilities, especially in satellite technology, mineralogy, instrument development, metallurgy, astronomy, ballistics, and physics. Prior to the Second World War, he taught physics at Fort Hayss, Kansas State College, and at Wayne University, and during the War ho was executive secretary of Division 4 of the National Defense Research Committee, which directed development of radio and photoelectric proximity fuses. Dr. Rinehart also directed a programme of ordnance research and development at the New Mexico School of Mines. Later, at the U.S. Naval Ordnance Test Station, China Lake, California, he carried out research on problems associated with fracture and deformation of materials subjected to high-speed impact and explosive forces. During 1954-55, Dr. Rinehart carried out research in the University of Cambridge. In July 1955 he joined the Smithsonian Astrophysical Observatory as its assistant director, whore he participated in the satellite tracking programme; he was also a research associate in astronomy at Harvard University, where he was concerned with meteorite research. Dr. Rinehart established the Mining Research Laboratory, Colorado School of Mines, in 1958. Born in Kirksville, Missouri, Dr. Rinehart went to the Northeast Missouri State Teachers College, whore he gained a B.S. degree in education and an A.B. in physics. Ho obtained his M.S. degree in physics at California Institute of Technology, and his Ph.D. in physics at the State University of Iowa.

\section{Botany at Queen Elizabeth College:}

\section{Prof. J. Edelman}

Dr. J. EDelman, who has been appointed to the chair of botany in the Department of Biology at Qucen Elizabeth College in the University of London, graduated in botany at the Imperial College of Science and Technology in 1948. Already intorosted in plant biochomistry, ho spent two years in Prof. (now Sir) Hans Krebs's Depart- 